\section{Zahlen des Monats}

\begin{abstract}
Hohe Schule
Um den akademischen Nachwuchs braucht sich die Nation offenbar keine Sorgen zu machen. Der Run auf deutsche Universitäten ist ungebrochen. Mehr noch: Im aktuellen Wintersemester sind hier zu Lande so viele Studierende an den Hochschulen eingeschrieben wie nie zuvor. Laut Statistischem Bundesamt sind nach ersten vorläufigen Ergebnissen rund 2.806.000 Studentinnen und Studenten immatrikuliert. Damit erhöhte sich die Zahl der Studierenden im Vergleich zum Wintersemester 2015/2016 um 48.300 (1,8 Prozent).
\end{abstract}

\section{Gutes Land}

Überhaupt ist die Bundesrepublik ein Magnet für Menschen aus anderen Nationen. 2015 sind so viele Personen nach Deutschland zugewandert wie seit der unmittelbaren Nachkriegszeit nicht mehr. Nach dem Migrationsbericht des Bundesamtes für Migration und Flüchtlinge registrierten die Behörden 2015 etwa 2,14 Millionen Zuzüge aus dem Ausland. Allerdings verließen im selben Jahr auch fast eine Million Menschen Deutschland. Die hohen Zuwanderungszahlen sind natürlich auf die vielen Flüchtlinge vor allem aus Syrien zurückzuführen. Dennoch waren 39 Prozent der Zuwanderer Ausländer aus Staaten der Europäischen Union.

\section{Sinnvolle PZR}

Äußerst gefragt ist in Deutschland auch die Professionelle Zahnreinigung (PZR). Eine Umfrage des Bewertungsportals Jameda hat ergeben, dass 65 Prozent der über 1.000 befragten Patienten mindestens einmal im Jahr diese Prophylaxe in Anspruch nehmen. Nur 16 Prozent haben eine derartige $\mathrm{Be}$ handlung eigenen Angaben zufolge noch nie durchführen lassen. Bei der Entscheidung für oder gegen Professionelle Zahnreinigung spielen die Kosten eine entscheidende große Rolle. 25 Prozent der 20- bis 29-Jährigen meinten, dass ihnen PZR schlichtweg zu teuer sei.

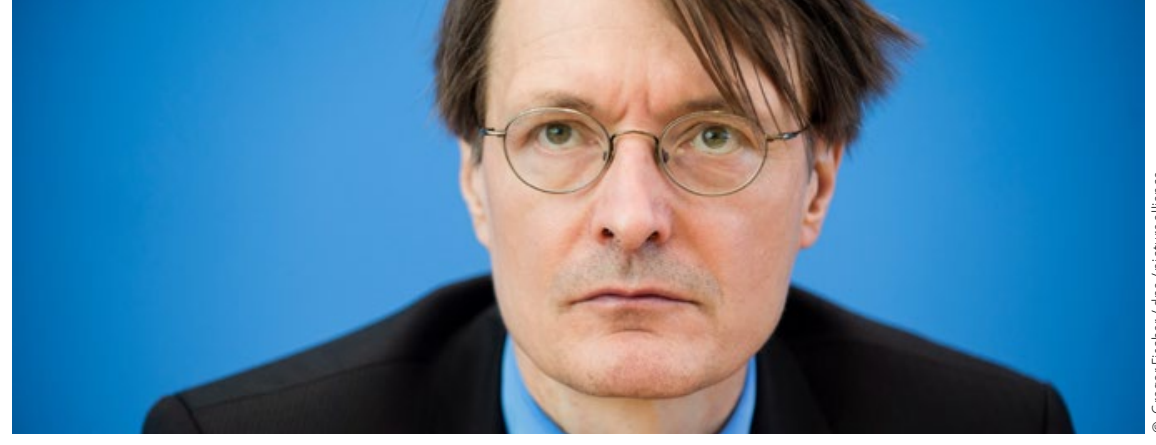

Pressegespräch zur Gesundheitspolitik

\title{
Lauterbach: „Das PKV-Modell ist nicht mehr zeitgemäß"
}

$\mathrm{Zu}$ einem gesundheitspolitischen Rundumschlag hat der SPD-Gesundheitsexperte und stellvertretende Fraktionsvorsitzende Karl Lauterbach kurz vor der Weihnachtspause in Berlin ausgeholt. Dabei standen die großen Themen der nun auslaufenden Legislaturperiode ebenso auf seiner Agenda wie Lauterbachs großes Zukunftsthema: Die Bürgerversicherung. In ihr sollen die heutigen gesetzlich Krankenversicherten ebenso wie die heute in der privaten Krankenversicherung (PKV) Vollversicherten gleichermaßen aufgehen.

Die Bürgerversicherung werde sicherer Bestandteil des neuen SPD-Programms zur Bundestagswahl werden. „Die PKV entwickelt sich zu einer Falle für die Versicherten", betonte Lauterbach. Sie sei ein regelhaftes Risiko für diejenigen, die im Alter über geringere Einkünfte verfügten. „Bis zu 1.200 Euro Beitragsprämie im Monat sind keine Seltenheit und ein Tarifwechsel ist meist keine Möglichkeit“, machte der SPD-Gesundheitsexperte deutlich. Seit Jahren verliere die PKV systematisch Mitglieder an die Gesetzliche Krankenversicherung (GKV), umgekehrt suchten nicht einmal annähernd so viele GKV-Versicherte den Weg in die private Vollversicherung. „Es kommt zu einem ungebremsten Kostenanstieg“, prognostizierte Lauterbach. Die Probleme der PKV seien strukturell bedingt und kaum zu beeinflussen: Zum einen sorge die anhaltende Niedrigzinsphase für Probleme bei den Altersrückstellungen, zum anderen habe die PKV ein doppeltes Demografieproblem. „Mit der Bürgerversicherung schaffen wir den Wechsel, denn dann gibt es keine zwei Klassen von GKV- und PKV-Versicherten mehr", warb Lauterbach für sein Modell. „Wir wollen nicht, dass die Versicherten Langfristgefangene einer PKV sind“, sagte der SPD-Fraktionsvize. „Das Modell PKVVollversicherung ist nicht mehr zeitgemäß.“

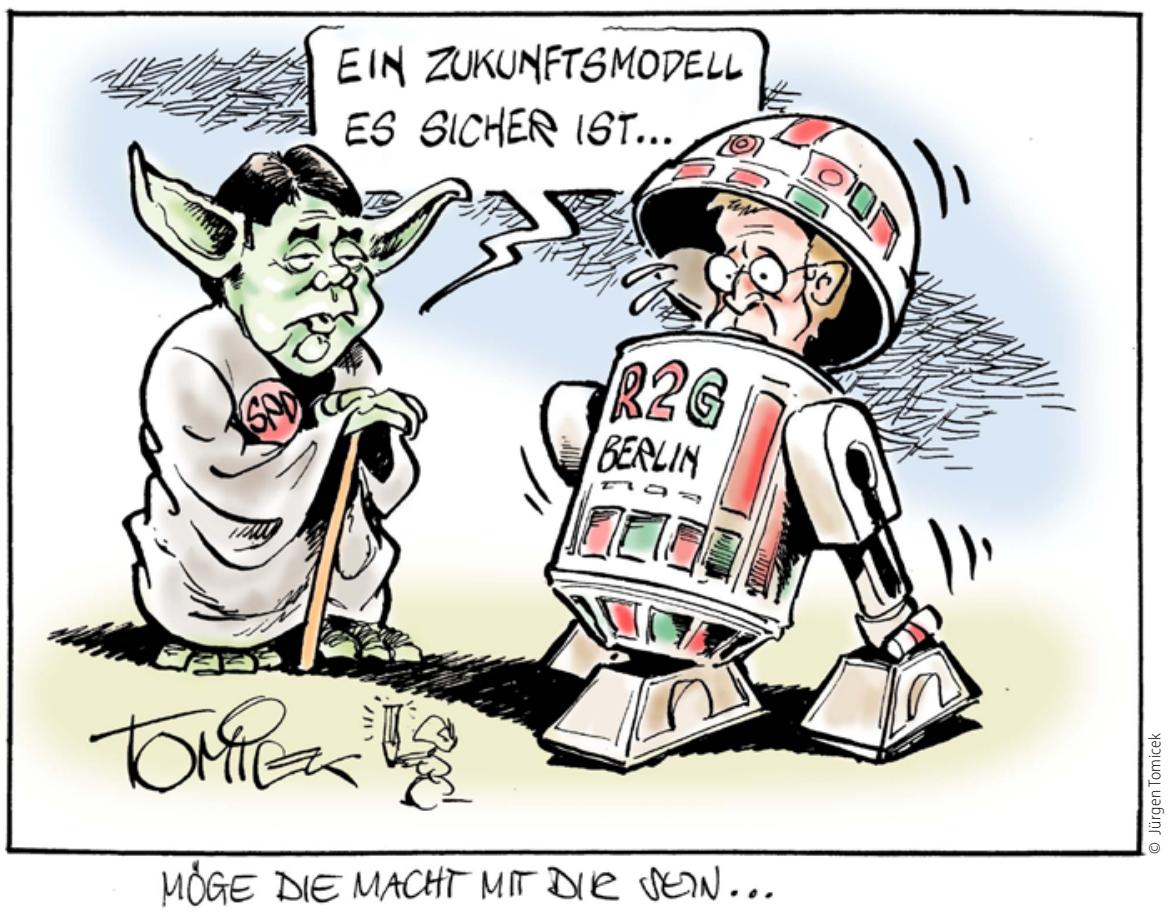

